\title{
LITERATURA NO ENSINO MÉDIO: CONEXÕES COM ORIENTAÇÕES CURRICULARES
}

Profa. Dra. Ivanda Maria Martins Silva

martins.ivanda@gmail.com Docente do Programa de Pós-graduação em Tecnologia e Gestão em Educação a Distância da Universidade Federal Rural de Pernambuco (UFRPE) 
RESUMO: No ensino médio, a literatura é vítima de processos inadequados de escolarização (SOARES, 1999), consolidados por meio de concepções, metodologias e orientações curriculares que evidenciam abordagens estereotipadas em relação à educação literária. As práticas de leituras e letramentos literários (COSSON, 2006) realizadas em sala de aula não encontram sintonia com aquelas que os estudantes desenvolvem na cibercultura (LÉVY, 1999), em contato com tecnologias digitais e novos suportes. Os professores revelam-se atônitos diante da necessidade de rever planejamentos didáticos e estratégias metodológicas para o trabalho com a literatura no ensino médio. As orientações curriculares, como PCN, OCNEM e BNCC, têm papel importante quando apresentam propostas em relação à literatura na escola. O objetivo principal do estudo aqui apresentado é analisar concepções subjacentes acerca da literatura em orientações curriculares, no sentido de refletir sobre o papel da literatura no currículo do ensino médio, considerando, também, a reforma do ensino médio, aprovada pela Lei $\mathrm{n}^{\mathrm{o}} 13.415 / 2017$.

PALAVRAS-CHAVE: ensino médio, literatura, currículo.

\section{LITERATURE IN HIGH SCHOOL: CONNECTIONS WITH CURRICULAR ORIENTATIONS}

ABSTRACT: In high school, literature is a victim of schooling inadequate processes (SOARES, 1999), consolidated through conceptions, methodologies and curricular guidelines that show stereotyped approaches to literary education. The reading and literacy practices (COSSON, 2006) conducted in the classroom are not in tune with those that students develop in cyberculture (LÉVY, 1999), in contact with digital technologies and new media. Teachers are astonished at the need to review didactic planning and methodological strategies for teaching literature in high school. Curricular guidelines, such as PCN, OCNEM and BNCC play an important role when presenting proposals in relation to literature in school. This study intends to analyze the underlying conceptions about the literature in curricular guidelines, in order to reflect on the literature role in the high school curriculum, considering also the reform approved by the Law $\mathrm{n}^{\circ} 13.415$ / 2017.

KEYWORDS: high school, literature, curriculum. 


\section{Considerações iniciais: a literatura no ensino médio}

Muitos estudos já foram realizados sobre o papel da literatura no ensino médio (REZENDE, 2013); (CEREJA, 2005); (PINHEIRO, 2001); (ROUXEL, 1996, 2013); (SILVA, 2005). Tais trabalhos apontam para o lugar pouco privilegiado que a literatura ocupa na sala de aula do nível médio, tendo em vista a imposição das leituras literárias idealizadas pelos professores, bem como as concepções estereotipadas que ainda circulam nos livros didáticos. Quase sempre abordada de forma superficial e fragmentada, a literatura é vítima do processo inadequado de escolarização (SOARES, 1999), o qual parece influenciar as práticas de letramento literário dos estudantes (COSSON, 2006).

No ensino médio, as aulas privilegiam a história da literatura, classificando-se rigidamente autores e obras em períodos literários, muitas vezes, abordados de forma desarticulada (SILVA, 2005). Em sala de aula, as práticas de letramento literário ainda são escolarizadas, considerando-se a enorme lista de livros paradidáticos que os estudantes precisam ler para realizar provas, exames, resumos, exercícios, preenchimento de fichas de leituras. Tais práticas não dialogam com aquelas que os alunos desenvolvem fora da escola, nos espaços virtuais, como a escrita de fanfics, a produção de blogs literários, a leitura de graphic novels, e tantas outras.

Os livros didáticos reforçam o processo de escolarização da literatura e não conseguem acompanhar o dinamismo das práticas de letramentos literários que os estudantes começam a desenvolver na cibercultura (LÉVY, 1999). Concordamos com Cereja (2005), quando aponta que o ensino de literatura, a partir dos livros didáticos, não alcança plenamente dois objetivos cruciais: a formação de leitores competentes de textos literários e a consolidação de hábitos de leitura. As concepções estereotipadas que circulam nos livros didáticos direcionam o ensino de literatura para enfoques formalistas/estruturalistas, os quais não valorizam as conexões entre autores, textos e leitores no ato da leitura literária.

Na cibercultura, a experiência estética dos leitores está influenciada pelas novas relações construídas nos espaços virtuais. O leitor em tela torna-se mais ativo, realizando leituras interativas que favorecem atitudes exploratórias e lúdicas (FREITAS, 2005). Na perspectiva de Cornis-Pope (2002), as tecnologias permitem que os alunos leiam de modo hipertextual, com maior liberdade para testar suas habilidades interpretativas, examinando e (re)construindo suas leituras. Essa liberdade interpretativa dos leitores 
precisa ser mais valorizada, compreendendo-se a leitura literária como jogo cooperativo entre autores/textos/leitores (ISER, 2002), repleto de indícios e subentendidos.

De acordo com essa perspectiva, a literatura não pode ser compreendida como um objeto fixo a ser contemplado, mas sim como experiência estética que surge na mente do leitor. A obra literária oferece oportunidade de o leitor se envolver numa experiência de reconstrução dos acontecimentos vividos pelas personagens. Os professores deveriam encorajar os alunos para que estes construam suas próprias experiências no ato da leitura.

O papel do professor é essencial ao selecionar obras que permitam uma interação mais produtiva, além de utilizar questões que possam deixar clara a relação entre a experiência do aluno e o texto (ROSENBLATT, apud JACOBUS, 1996, p.141). Conforme Kramsch (1996, p.134), os alunos precisam entender o texto literário como uma forma de (re)descoberta de sua própria identidade, por meio da reescrita que se concretiza no ato de ler, momento em que o leitor responde ativamente ao texto. Nesse sentido, a leitura é compreendida como ato de (re)construção textual, etapa importante para o leitor produzir sentidos a partir da polissemia da obra literária.

Edmonds e Skerrett (1996, p.140) defendem que o professor pode usar a literatura como um meio de os alunos interpretarem a si próprios, considerando a interação entre textos e leitores. Em sintonia com essas abordagens, a noção de mock reader, espécie de leitor pressuposto pela configuração textual, revela-se importante quando se pensa no papel ativo do leitor da obra literária (GIBSON,1986). Segundo Gibson (1986), uma das tarefas do professor de literatura é ampliar as possibilidades de leitura frente ao texto literário, no sentido de os alunos assumirem papéis distintos diante da leitura de cada novo texto. Certamente as concepções estigmatizadas de literatura que ainda circulam na escola e são disseminadas nos livros didáticos vão direcionando "horizontes e expectativas de leitura literária" (JAUSS, 1994, p.23).

Conforme Ramos e Zanolla (2008), os livros didáticos de literatura revelam informações sobre o contexto em que a obra literária foi produzida e publicada, dados biográficos do autor, o movimento literário em que a obra se insere, mas não colocam o leitor em interação com o texto. Ainda na visão desses autores, os livros didáticos analisam trechos de algumas obras literárias, apontam recursos linguísticos e gramaticais empregados na elaboração dos textos literários, mas não conseguem oferecer ao leitor a experiência estética da leitura literária. 
A forma como a literatura vem sendo abordada na sala de aula do ensino médio é reflexo das concepções estereotipadas que circulam na escola e nos livros didáticos, bem como nas orientações curriculares propostas para a educação básica. Em documentos, como Orientações Curriculares Nacionais para o Ensino Médio (BRASIL, 2006), Parâmetros Curriculares Nacionais (BRASIL, 1998, 1999, 2002) e Base Nacional Comum Curricular (BRASIL, 2016) e outros, a literatura assume posição periférica, sendo abordada essencialmente como objeto estético, ancorado em práticas de linguagem e integrado ao ensino de língua portuguesa, como veremos a seguir.

\section{A literatura nas orientações curriculares do ensino médio}

O currículo do ensino médio é continuamente discutido e alguns documentos oficiais revelam-se como norteadores para os docentes que buscam repensar constantemente sua prática pedagógica com base em suportes teóricos e metodológicos.

As Orientações Curriculares para o Ensino Médio (BRASIL, 2006) apresentam os conhecimentos de literatura, justificando que os PCN+ (BRASIL, 2002), “[...] ao incorporarem no estudo da linguagem os conteúdos de Literatura, passaram ao largo dos debates que o ensino de tal disciplina vem suscitando, além de negar a ela a autonomia e a especificidade que lhe são devidas." (BRASIL, 2006, p. 49). Percebemos a crítica apresentada nas Orientações Curriculares para o Ensino Médio (BRASIL, 2006) em relação ao espaço ainda limitado que a literatura ocupou nos PCN+ (BRASIL, 2002), o que reforça a necessidade de se repensar o currículo com base nas contribuições dos estudos direcionados à obra literária.

As Orientações Curriculares Nacionais Gerais da Educação Básica (BRASIL, 2013, p. 189) também evidenciam o papel "periférico" da literatura nos documentos oficiais, quando, na proposta das Diretrizes Curriculares para o Ensino Médio, retoma os componentes curriculares obrigatórios previstos na LDB (BRASIL, 1996) que integram as áreas de conhecimento: "I - Linguagens: a) Língua Portuguesa. b) Língua Materna, para populações indígenas. c) Língua Estrangeira moderna. d) Arte, em suas diferentes linguagens: cênicas, plásticas e, obrigatoriamente, a musical. e) Educação Física." Nesse documento, a literatura é contemplada no campo "Linguagens", integrando-se ao componente curricular obrigatório "Língua Portuguesa". 
O documento orientador do Programa Ensino Médio Inovador (BRASIL, 2016, p.15) propõe que o currículo do ensino médio seja organizado a partir de um eixo comum - "trabalho, ciência, tecnologia e cultura" -, buscando-se integrar os conhecimentos e os componentes curriculares na organização do trabalho pedagógico. Nesse sentido, também a literatura ocupa espaço timidamente marcado no macrocampo "leitura e letramento", descrito a seguir:

\begin{abstract}
As ações propostas neste macrocampo estarão intrinsecamente relacionadas a todas as áreas de conhecimento do currículo (Linguagens, Ciências Humanas, Ciências da Natureza e Matemática). É fundamental que os estudantes desenvolvam habilidades de leitura, interpretação e produção de textos em diversos gêneros, assim é importante ter foco na criação de estratégias para desenvolvimento da leitura crítica e da organização da escrita em formas mais complexas, ampliando as situações de uso da leitura e da escrita, incluindo estudos científicos e literários, obras e autores locais, nacionais e internacionais. (BRASIL, 2016, p. 17).
\end{abstract}

Os Parâmetros Curriculares Nacionais (PCN) também são documentos orientadores das práticas direcionadas ao tratamento dado à literatura na educação básica. Podemos observar que, do ensino fundamental ao ensino médio, os PCN revelam concepções similares sobre a natureza e a função da literatura. Vale notar que os PCN do ensino fundamental (BRASIL, 1998) tecem um número maior de considerações sobre o texto literário, ao passo que a proposta curricular do ensino médio (BRASIL, 1999) trata ligeira e superficialmente das questões literárias. Isso nos parece um paradoxo, uma vez que, no ensino médio, o estudo da literatura está mais evidenciado na organização curricular e necessita de orientações mais aprofundadas para que os professores consigam rever estratégias e metodologias direcionadas às práticas de leitura e letramentos dos estudantes.

Não estamos querendo desmerecer o papel da literatura no ensino fundamental, mas é geralmente, no ensino médio, que os alunos começam a acompanhar os estudos literários previstos na matriz curricular, com maior densidade e aprofundamento. Se, desde o ensino fundamental, os alunos tivessem uma melhor orientação para a leitura literária, certamente não encontrariam muitos obstáculos no ensino médio, quando entrassem em contato com as obras representativas do cânone literário, por exemplo.

De modo geral, no ensino médio, podemos notar a falta de interesse dos alunos pela leitura literária e a carência de um repertório de leituras prévias. Os professores também encontram dificuldades no trabalho com a leitura literária, devido à escassez de discussões metodológicas capazes de subsidiar a prática pedagógica em sala de aula. 
Os PCN do ensino médio assumem especial relevância no trabalho de orientação dos docentes que necessitam de uma proposta capaz de nortear o trabalho em sala de aula. Contudo, nos PCN do ensino médio (BRASIL, 1999), a proposta dada ao professor é muito sintética e descontextualizada. Em apenas seis páginas, apresentam-se conhecimentos, competências e habilidades direcionados para o ensino de Língua Portuguesa/Literatura.

Os PCN propõem que o estudo de língua portuguesa, assim como o de literatura devem manter uma interação, a fim de que o aluno perceba o diálogo entre as práticas de linguagem (leitura, produção de textos, análise linguística e literatura). No entanto, sabemos que, na prática de sala de aula, essa integração geralmente não ocorre, principalmente no ensino médio, em função de uma organização curricular que subdivide o ensino de língua portuguesa em aulas de redação, literatura e análise linguística. Essa estrutura curricular influencia o tratamento dado ao texto literário, muitas vezes analisado de forma descontextualizada, sem levar o aluno a perceber as conexões dialógicas entre autor-obra-leitor, ou ainda, sem que a literatura seja compreendida associada a outras áreas do conhecimento, com enfoques transdisciplinares e transversais.

Nos PCN do ensino médio (BRASIL, 1999), apenas encontramos uma vaga referência ao tratamento dado ao texto literário no contexto escolar.

\begin{abstract}
A história da literatura costuma ser o foco da compreensão do texto; uma história que nem sempre corresponde ao texto que lhe serve de exemplo. $\mathrm{O}$ conceito de texto literário é discutível. Machado de Assis é literatura, Paulo Coelho não. Por quê? As explicações não fazem sentido para o aluno. Outra situação de sala de aula pode ser mencionada. Solicitamos que os alunos separassem de um bloco de textos, que iam desde poemas de Pessoa e Drummond até contas de telefones e cartas de banco, textos literários e nãoliterários, de acordo como são definidos. Um dos grupos não fez qualquer separação. Questionados, os alunos responderam: “Todos são não-literários, porque servem apenas para fazer exercícios na escola.” E Drummond? Responderam: "Drummond é literato, porque vocês afirmam que é, eu não concordo. Acho ele um chato. Por que Zé Ramalho não é literatura? Ambos são poetas, não é verdade? (BRASIL, 1999, p.137).
\end{abstract}

Como podemos observar, os PCN tentam apresentar uma visão ampla da literatura, partindo de uma experiência em sala de aula, na qual a participação do aluno é fundamental para se desmistificar o conceito tradicional de texto literário. Ao definir a literatura, tomando como ponto de partida a especificidade do discurso literário, como vimos, os PCN do ensino fundamental mostram uma visão anacrônica dos estudos literários, fundada nos moldes formalistas, ao passo que a proposta do ensino médio tenta 
passar uma concepção mais abrangente, considerando a relatividade do conceito de literatura. A noção de literatura revelada nos PCN do ensino médio parece destoar da visão sobre a especificidade do texto literário presente na proposta do ensino fundamental, o que evidencia uma falta de articulação entre os pressupostos teóricos apresentados para os diferentes níveis de ensino (fundamental e médio).

$\mathrm{Na}$ citação em foco, a visão do aluno a respeito do texto literário soa como artificial, é como se o exemplo servisse apenas para afirmar que "o conceito de texto literário é discutível". No entanto, o documento não oferece um aprofundamento de questões mais amplas sobre a intencionalidade estética do autor, os modos de circulação do texto (editoração, publicação, críticas especializadas etc.), bem como a recepção do leitor. Em síntese, os PCN do ensino fundamental e do ensino médio revelam certas concepções relacionadas ao texto literário que devem ser repensadas.

Outro documento importante e bastante atual nas reflexões sobre o currículo é a Base Nacional Comum Curricular (BRASIL, 2016) ${ }^{1}$, orientação de caráter normativo que define o conjunto orgânico e progressivo de aprendizagens e competências essenciais para os estudantes ao longo das etapas e modalidades da educação básica.

Também nas orientações da Base Nacional Comum Curricular (BNCC), a literatura ainda não encontra muitos destaques. A BNCC contempla as reflexões sobre a literatura na área de linguagens, tendo em vista as conexões com o estudo da língua portuguesa no ensino médio. $\mathrm{O}$ documento ressalta a fragmentação curricular no campo de língua portuguesa, como observamos na citação a seguir:

No Ensino Médio, o componente curricular Língua Portuguesa - a exemplo dos demais componentes - precisa lidar com o agravamento da fragmentação do conhecimento. Essa fragmentação - não obstante o esforço de constituição de áreas do conhecimento, já propostas nas Diretrizes Curriculares para o Ensino Médio de 1998 (BRASIL, 1998) - é desafio a ser enfrentado ainda hoje e pode ser observada mesmo no interior do componente, em separações que isolam, por exemplo, práticas de escrita, de práticas com a literatura, ou de estudos sobre a língua. (BRASIL, 2016, p. 505).

\footnotetext{
${ }^{1}$ Em abril de 2017, o MEC entregou a versão final da Base Nacional Comum Curricular (BNCC) ao Conselho Nacional de Educação (CNE). A BNCC passará por aprovação do CNE, responsável pela elaboração de parecer e projeto de resolução sobre a BNCC. Informações sobre a BNCC estão disponíveis em: 〈http://basenacionalcomum.mec.gov.br〉.
} 
Com essa visão, a BNCC propõe que os objetivos de aprendizagem e desenvolvimento da língua portuguesa no ensino médio apresentem-se organizados em quatro eixos: oralidade, leitura, escrita e conhecimentos sobre língua/norma padrão. A literatura não é proposta como eixo, mas sim como campo de atuação em que as práticas de linguagem se realizam. Nesse sentido, a BNCC comenta sobre os campos "literário, político-cidadão e investigativo", visando às diversas formações para o estudante do ensino médio, ou seja, uma formação estética, por meio do contato com a literatura; além de "[...] uma formação para o exercício da cidadania, que envolve a condição de se inteirar dos fatos do mundo, opinar e agir sobre eles; uma formação que contempla a produção do conhecimento e a pesquisa." (BRASIL, 2016, p. 506).

Com base nessa organização, “[...] o campo literário envolve as práticas com textos que possibilitem a fruição de produções literárias e favoreçam experiências estéticas.” (BRASIL, 2016, p. 506). Nesse sentido, a literatura é destacada em sua função estética, como fenômeno artístico capaz de promover a fruição e a experiência estética, por meio do contato dos estudantes com a diversidade de textos, gêneros e obras literárias.

A ênfase do trabalho com literatura é pautada na leitura como eixo central nas “[...] práticas com o literário no Ensino Médio. Embora a escrita literária também esteja presente, não se tem como objetivo uma formação para a escrita literária." (BRASIL, 2016, p. 508). Outro ponto importante na BNCC é o destaque à leitura de textos/obras do cânone literário, como observamos na citação a seguir: "o Ensino Médio é, portanto, a etapa da Educação Básica em que se enfatiza a leitura de clássicos da literatura brasileira, já iniciada no Ensino Fundamental, sobretudo nos anos finais.” (BRASIL, 2016, p. 508).

É importante destacar que as concepções de literatura subjacentes às orientações curriculares da BNCC do ensino médio reforçam visões estigmatizadas que podem orientar o ensino de literatura. Sem reflexões sobre as funções políticas, históricas e sociais que a literatura revela no processo dialógico de interação com a sociedade, compreendendo-se o dialogismo em sua acepção mais ampla (BAKHTIN, 1993), as orientações curriculares da BNCC tratam o fenômeno literário como objeto de linguagem, em sua dimensão puramente estética.

É fundamental que os estudantes percebam as dimensões dialógicas e polifônicas (BAKHTIN, 1993) da literatura, compreendendo as vozes sociais representadas mimeticamente nas obras literárias, bem como percebendo as relações entre autores, 
obras e leitores, ancoradas em processos socioculturais e históricos. As leituras dos estudantes precisam ser mais valorizadas no espaço de sala de aula, ampliando-se a compreensão da leitura literária como processo de negociação e (re)construção de sentidos, em que o leitor tem papel fundamental. (ISER, 2002; JAUSS, 1994).

As dimensões simbólicas e políticas no ato da leitura literária precisam ser mais evidenciadas, articulando-se com a função estética da literatura e sua natureza translinguística (BAKHTIN, 1993). Acreditamos que destacar apenas a literatura como objeto de linguagem poderá contribuir para práticas inadequadas de escolarização do texto literário (SOARES, 1999), quando este assume a função de pretexto para o ensino de elementos da análise linguística, sem que sejam devidamente consideradas as articulações com abordagens mais amplas, tendo em vista propostas dialógicas, sociológicas, psicanalíticas, antropológicas, intersemióticas, simbólicas e tantas outras direcionadas às análises do texto literário.

A visão da BNCC para o trabalho com a literatura no ensino médio revela sintonia com aquela apresentada para os anos finais do ensino fundamental. A BNCC para os anos finais do ensino fundamental aborda a literatura no eixo "educação literária", buscando conexões com a "leitura". Em relação ao eixo "leitura", a BNCC aponta para a ênfase no desenvolvimento e na aprendizagem de habilidades de compreensão e interpretação de textos variados. Quanto ao eixo "educação literária", o foco principal é a formação de leitores capazes de "[...] apreciar textos literários orais e escritos, de autores de língua portuguesa e de traduções de autores de clássicos da literatura internacional." (BRASIL, 2016, p. 65).

Notamos que o documento aponta para uma concepção generalizada da literatura, sem aprofundar reflexões teóricas ou metodológicas direcionadas à educação literária. A própria noção de educação literária é proposta, mas não há comentários ou referências a pesquisas direcionadas a tal conceito, buscando-se, por exemplo, conexões com práticas de leituras e letramentos literários que os alunos deveriam construir na educação básica, com aprofundamento no contexto do ensino médio. A BNCC aponta que o primordial não seria o "ensino de literatura", mas sim a necessidade de a escola promover o "contato com a literatura para a formação do leitor literário", como podemos observar na citação a seguir: 


\begin{abstract}
Não se trata, pois, no eixo Educação literária, de ensinar literatura, mas de promover o contato com a literatura para a formação do leitor literário, capaz de apreender e apreciar o que há de singular em um texto cuja intencionalidade não é imediatamente prática, mas artística. O leitor descobre, assim, a literatura como possibilidade de fruição estética, alternativa de leitura prazerosa. Além disso, se a leitura literária possibilita a vivência de mundos ficcionais, possibilita também ampliação da visão de mundo, pela experiência vicária com outras épocas, outros espaços, outras culturas, outros modos de vida, outros seres humanos. (BRASIL, 2016, p. 65).
\end{abstract}

Como podemos notar, não fica clara a distinção que o documento propõe entre educação literária e ensino de literatura, o que certamente pode propiciar futuramente amplos debates, no sentido de se investigar, de fato, qual a proposta da BNCC para o trabalho com a literatura na escola. Sob esse aspecto, é importante revisitarmos a abordagem de Beach e Marshall (1991) que apontam para distinções entre a leitura da literatura e o ensino da literatura. Segundo os autores, a leitura da literatura está relacionada à compreensão do texto, à experiência literária vivenciada pelo leitor no ato da leitura, ao passo que o ensino da literatura se configura como o estudo da obra literária, tendo em vista a sua organização estética. (BEACH e MARSHALL, 1991, p.38).

Na verdade, esses dois níveis estão imbricados, na medida em que, ao experienciar o texto, por meio da leitura literária, o aluno também deveria ser instrumentalizado, a fim de reconhecer a literatura como objeto esteticamente organizado. No entanto, a escola parece dissociar esses dois níveis, desvinculando o prazer de ler o texto literário (produzido pela leitura da literatura) do reconhecimento das singularidades estéticas da obra (proporcionado pelo estudo/ensino da literatura).

É preciso que a escola amplie o leque de atividades, visando à leitura da literatura como atividade lúdica de construção e reconstrução de sentidos. O aluno-leitor deve sentir-se motivado a ler o texto independentemente da imposição das tarefas escolares. Contudo, parece-nos que o contexto escolar privilegia mais o ensino da literatura, no qual a leitura realizada pelos professores é diferente daquela efetivada pelos alunos, pois a diversidade de repertórios, conhecimento de mundo, experiências de leitura influenciam diretamente o contato do leitor com o texto. Tanto a leitura da literatura quanto o ensino da literatura deveriam estar presentes no contexto escolar de modo articulado, pois são dois níveis dialeticamente relacionados. 
Tendo em vista as ideias de Beach e Marshall (1991), parece-nos que as orientações da BNCC reforçam a importância da leitura da literatura, mas não promovem articulações com o ensino de literatura, no sentido de ampliar o debate sobre a necessidade de instrumentalizar professores e alunos para a construção de relações mais dinâmicas e significativas com o fenômeno literário.

Em linhas gerais, os documentos norteadores apresentam o desenho curricular do ensino médio, evidenciando o tratamento ainda "tímido" dado à literatura, buscando-se associar as reflexões sobre o ensino de literatura às dimensões, como: linguagem, língua portuguesa, leitura e letramento. As orientações curriculares ainda precisam ampliar o debate sobre reflexões teóricas e didático-metodológicas, no sentido de fornecer subsídios para os docentes repensarem sua prática pedagógica direcionada ao estudo do texto literário em sala de aula.

As reflexões sobre literatura propostas pela BNCC serão fundamentais para ampliar o debate sobre a reforma do ensino médio, considerando a Lei ${ }^{\circ} 13.415$, de 16 de fevereiro de 2017, a qual aprovou a medida provisória 746, que instituiu a política de fomento à implementação de escolas de ensino médio em tempo integral, conforme veremos a seguir.

\section{Reforma do ensino médio: ainda há espaço para a literatura?}

Em 22 de setembro de 2016, o MEC lançou a medida provisória $n^{\circ} 746$, que instituiu a política de fomento à implementação de escolas de ensino médio em tempo integral, alterando a Lei $\mathrm{n}^{\circ}$ 9.394, de 20 de dezembro de 1996, que estabelece as diretrizes e bases da educação nacional, e a Lei no 11.494 de 20 de junho 2007, que regulamenta o Fundo de Manutenção e Desenvolvimento da Educação Básica e de Valorização dos Profissionais da Educação, e dá outras providências.

Nesse documento, é lançada a reforma curricular do ensino médio, com a proposta de ampliar a "[...] carga horária para mil e quatrocentas horas, observadas as normas do respectivo sistema de ensino e de acordo com as diretrizes, os objetivos, as metas e as estratégias de implementação estabelecidos no Plano Nacional de Educação.” (BRASIL, MP 746/ 2016). 
Ressaltamos que a proposição da reforma do ensino médio, por meio de uma medida provisória, foi alvo de amplas críticas pelos estudiosos da educação e pela sociedade em geral, visto que não houve um amplo debate com professores, alunos, especialidades e comunidade em geral sobre tal proposta.

Logo que lançada a medida provisória, as críticas foram intensas, principalmente em relação aos componentes curriculares relativos, sobretudo, a Artes e Educação Física, os quais, na primeira versão do documento, foram descritos como componentes curriculares sem a obrigatoriedade para o ensino médio. Posteriormente, o Ministério da Educação (MEC) revisou a proposta e adaptou o texto, colocando nova redação que agora contempla Artes e Educação Física como componentes curriculares obrigatórios no currículo do ensino médio.

Em 16 de fevereiro de 2017, a Lei $\mathrm{n}^{\mathrm{o}} 13.415$ foi aprovada com o propósito de alterar a LDB 9.394, de 20 de dezembro de 1996, fazendo valer a proposta da medida provisória $\mathrm{n}^{\circ} 746 / 2016$ que institui a política de fomento à implementação de escolas de ensino médio em tempo integral. Conforme essa nova legislação, o currículo do ensino médio é organizado em conteúdos comuns e especificidades, considerando o itinerário formativo selecionado pelo estudante, com base nas áreas de: linguagens, matemática, ciências da natureza, ciências humanas e formação técnica.

No desenho curricular proposto, os componentes "Língua Portuguesa" e "Matemática" permanecem obrigatórios nos três anos do ensino médio, como também Artes e Educação Física, as quais tinham sido excluídas pelo texto original da medida provisória. Entre as línguas estrangeiras, o "Espanhol” não será mais obrigatório, ao contrário do "Inglês", que continua obrigatório a partir do $6^{\circ}$ ano do ensino fundamental. Uma mudança significativa envolveu os componentes "Filosofia" e "Sociologia", que passarão a ser obrigatórios apenas na BNCC, fato este que aponta para o perfil do aluno do ensino médio que se deseja formar, priorizando-se o itinerário técnico atrelado ao imediatismo do mercado de trabalho, em lugar de uma formação mais global e humanística.

Com base nesse novo desenho curricular, a Lei ${ }^{\circ} 13.415 / 2017$, em seu Art. $4^{\circ}$, altera o Art. 36 da Lei n ${ }^{\circ}$ 9.394, de 20 de dezembro de 1996, passando a vigorar com as seguintes alterações: 
Art. 36. O currículo do ensino médio será composto pela Base Nacional Comum Curricular e por itinerários formativos, que deverão ser organizados por meio da oferta de diferentes arranjos curriculares, conforme a relevância para o contexto local e a possibilidade dos sistemas de ensino, a saber:

I - linguagens e suas tecnologias;

II - matemática e suas tecnologias;

III - ciências da natureza e suas tecnologias;

IV - ciências humanas e sociais aplicadas;

$\mathrm{V}$ - formação técnica e profissional.

$\S 1^{\circ}$ A organização das áreas de que trata o caput e das respectivas competências e habilidades será feita de acordo com critérios estabelecidos em cada sistema de ensino. (BRASIL, Lei no $13.415 / 2017$ ).

Como observamos, o eixo "V- formação técnica e profissional" foi incluído nessa nova proposta curricular do ensino médio, o que aponta para retrocessos, se considerarmos o ensino médio como etapa de mediação e formação do estudante para os padrões da educação superior, em que os pilares ensino, pesquisa e extensão deveriam ser abordados desde muito cedo na escola básica. Ao incluir a formação técnica e profissional para o estudante do ensino médio, o governo parece tentar voltar a uma proposta fordista de educação, formando mão de obra para o mercado, em um curto espaço de tempo, adiando, talvez, o ingresso do estudante nos centros de pesquisa e nas universidades.

Diante desse cenário, qual o papel reservado à literatura na formação do estudante do ensino médio? Em linhas gerais, a reforma proposta para o ensino médio aponta para a integração entre o currículo do ensino médio e a Base Nacional Comum Curricular, com ênfase nas seguintes áreas do conhecimento: I - linguagens; II - matemática; III - ciências da natureza; IV - ciências humanas; e V - formação técnica e profissional. Nessa proposta, a literatura surge integrada à área de linguagens, articulando-se ao ensino de Língua Portuguesa, compreendendo-se este como componente curricular obrigatório. Nesse cenário de alterações na organização curricular do ensino médio, a literatura, mais uma vez, ocupa lugar periférico nas discussões, pois é compreendida como objeto de linguagem, como vimos nas orientações da BNCC (2016).

\section{Considerações Finais}

Acreditamos que o papel reservado à literatura na nova organização curricular do ensino médio está atrelado à forma como as unidades de ensino irão interpretar as orientações curriculares propostas pela BNCC e pela Lei $n^{\circ}$ 13.415/2017. É importante que seja realizado amplo debate entre gestores, professores, estudantes e comunidade em geral sobre a reforma, no sentido de se pensar que perfil de aluno se deseja formar durante as ações propostas nos três anos do ensino médio. 
A Lei $n^{\circ}$ 13.415/2017, em seu Art. 36, inciso $5^{\circ}$ afirma:

Os currículos do ensino médio deverão considerar a formação integral do aluno, de maneira a adotar um trabalho voltado para a construção de seu projeto de vida e para a sua formação nos aspectos cognitivos e socioemocionais, conforme diretrizes definidas pelo Ministério da Educação. (BRASIL, 2017).

Observemos, na citação acima, a ênfase às "diretrizes definidas pelo Ministério da Educação" em relação à orientação curricular e à "formação integral do aluno" do ensino médio. Enquanto as diretrizes estiverem apenas atreladas às dimensões políticas dos poderes que regem a educação no país, como o Ministério da Educação, certamente o potencial transformador da educação ficará limitado, se professores, gestores, estudantes e a comunidade não participarem efetivamente dos planejamentos e da elaboração de projetos/propostas direcionadas às demandas de cada escola.

Nesse sentido, se a escola tiver como projeto a formação holística de estudantes, considerando a importância da integração entre diversas áreas do conhecimento, a literatura sempre terá seu espaço garantido, independente de as reflexões sobre o literário ainda serem superficiais ou periféricas nos documentos curriculares. Como propôs Barthes (1980), a literatura precisa ser compreendida em sua natureza interdisciplinar: "Se, por não sei que excesso de socialismo ou barbárie, todas as nossas disciplinas devessem ser expulsas do ensino, exceto uma, é a disciplina literária que deveria ser salva, pois todas as ciências estão presentes no monumento literário”. (BARTHES, 1980, p. 1617).

É justamente essa visão ampla da literatura que precisa ser mais valorizada no espaço escolar, no sentido de propiciar a construção de relações mais significativas dos estudantes/leitores com as obras literárias, reconhecendo o valor não apenas estético/linguístico da literatura, mas, sobretudo, o potencial transformador da leitura literária como ato político, simbólico, ideológico, histórico e sociocultural. 


\section{REFERÊNCIAS BIBLIOGRÁFICAS}

BAKHTIN, M. Questões de literatura e de estética: a teoria do romance. São Paulo: Unesp, 1993.

BARTHES, R. Aula. São Paulo: Cultrix, 1980.

BRASIL. Lei n⿳ 9.394/96. Lei de diretrizes e bases da educação nacional. Brasília, 1996.Disponível em: <http://www.planalto.gov.br/ccivil_03/leis/L9394.htm>. Acesso em: 20 fev. 2015.

BRASIL. Medida provisória $\mathrm{n}^{\circ}$ 746, de 22 de setembro de 2016. Disponível em $<$ http://www.planalto.gov.br/ccivil_03/_ato2015-

2018/2016/Mpv/mpv746impressao.htm>. Acesso em: 20 outubro de 2016.

BRASIL. Lei $\mathbf{n}^{\mathbf{0}}$ 13.415, de 16 de fevereiro de 2017. Disponível em: $<$ http://legis.senado.leg.br/legislacao/ListaTextoSigen.action? norma=602639\&id=1437 4947\&idBinario=15657824\&mime=application/rtf $>$. Acesso em: 12 de março de 2017.

BRASIL. Base Nacional Comum Curricular (BNCC). Segunda versão revista. Brasília: MEC, 2016. Disponível em: <http://basenacionalcomum.mec. gov.br/documentos/bncc-2versao.revista.pdf>. Acesso em: 23 mar. 2017.

BRASIL. Orientações curriculares para o ensino médio (OCNEM): Linguagens, códigos e suas tecnologias. Brasília: Ministério da Educação, Secretaria de Educação Básica, volume 1. 2006. 239 p.

BRASIL. PCN + Ensino Médio: Linguagens, códigos e suas tecnologias. Orientações Educacionais Complementares aos Parâmetros Curriculares Nacionais. Brasília: Ministério da Educação, Secretaria de Educação Básica, volume 1. 2002. 241 p..

BRASIL. Parâmetros Curriculares Nacionais (PCN): $3^{\circ}$ e $4^{\circ}$ ciclos do ensino fundamental: língua portuguesa. Brasília: MEC/SEF, 1998 b.

BRASIL. Parâmetros Curriculares Nacionais (PCN): Ensino Médio. Brasília, DF: MEC/SEMTEC, 1999.

BRASIL. Diretrizes Curriculares Nacionais Gerais da Educação Básica. Brasília: MEC, SEB, DICEI, 2013. Disponível em:<http://portal.mec.gov.br/docman/julho-2013pdf/13677-diretrizes-educacao-basica-2013-pdf/file〉. Acesso em 15 maio 2016.

BRASIL/MEC. Programa Ensino Médio Inovador: documento orientador. Brasília: MEC, 2016. Disponível em: <http://portal.mec.gov.br/docman/novembro-2016pdf/50311-documento-orientador-adesao-20162017-pdf/file>. Acesso em 12 fev 2017.

CEREJA, W. Ensino de Literatura: uma abordagem dialógica para o trabalho com a literatura. São Paulo: Atual, 2005.

CORNIS-POPE, M. Literary education in the age of hypertextual and networked communication: strategies for an interactive critical pedagogy. E-magazine LiterNet, n. 2, v. 3. 2000. 
COSSON, R. Letramento literário: teoria e prática. São Paulo: Contexto, 2006.

EDMONDS, C.; SKERRETT, J. Literary Theory and Literature Teachers: New Life for Introductory Courses. In: JACOBUS, Lee. (Org.) Teaching literature: a collection of essays on theory and practice. New Jersey: Prentice Hall, 1996. p.137 - 158.

FREITAS, M. T. Leitura, escrita e literatura em tempos de internet. In: PAIVA, Aparecida et al (Orgs.). Literatura e Letramento: espaços, suportes e interfaces- o jogo do livro. Belo Horizonte: Autêntica, 2005. p.155 - 173.

GIBSON, W. Authors, speakers, readers and mock readers. In: TOMPKINS, J. (Ed.). Reader-response criticism: from formalism to post-structuralism. Baltimore: The Johns Hopkins University Press, 1986. p. 01 - 06.

ISER, W. O jogo do texto. In: LIMA, L. C. A literatura e o leitor. Rio de Janeiro; Paz e Terra. 2a ed., p.105-118, 2002.

JACOBUS, L. (Org.). Teaching literature: a collection of essays on theory and practice. New Jersey: Prentice Hall, 1996.

JAUSS, H. R. A História da Literatura como provocação à Teoria Literária. São Paulo: Ática, 1994.

KRAMSCH, C. Literature Texts in the Classroom: A Discourse. In: JACOBUS, Lee. (Org.) Teaching literature: a collection of essays on theory and practice. New Jersey: Prentice Hall, 1996. p.121-144.

LÉVY, P. Cibercultura. São Paulo: Editora 34, 1999.

PINHEIRO, J. H. Literatura no ensino médio: uma hipótese de trabalho. In: Dias, L. F. (org.). Texto, escrita, interpretação: ensino e pesquisa. João Pessoa: Ideia, 2001.

RAMOS, F.; ZANOLLA, T. Repensando a aula de Literatura no Ensino Médio: a interação texto-leitor como centro. Cadernos do Aplicação, Porto Alegre, v. 21, n. 2, jan./jun. 2008.

REZENDE, N. O ensino de literatura e a leitura literária. In: DALVI, M.; REZENDE, N.; JOVER-FALEIROS, R. (orgs.). Leitura de literatura na escola. São Paulo: Parábola, 2013, pp.99-112.

ROUXEL, A. Enseigner la lecture littéraire. Rennes: Presses Universitaires de Rennes, 1996.

ROUXEL, A. Aspectos metodológicos do ensino da literatura. In: DALVI, M.; REZENDE, N.; JOVER-FALEIROS, R. (orgs.). Leitura de literatura na escola. São Paulo: Parábola, 2013.

SILVA, I. Literatura em sala de aula: da teoria à prática escolar. Recife: Programa de Pós-graduação em Letras da UFPE. Coleção Teses, 2005. 
SOARES, M. A escolarização da literatura infantil e juvenil. In: Evangelista, A. et al. (org.). A escolarização da leitura literária: o jogo do livro infantil e juvenil. Belo Horizonte: Autêntica, 1999.

Recebido em: 01/06/2017

Aceito em: 05/11/2017 